\title{
Full-text Linking: Affiliated versus Nonaffiliated Access in a Free Database
}

\section{Jill E. Grogg, Debra K. Andreadis, and Rachel A. Kirk}

\begin{abstract}
This article presents a comparison of access to full-text articles from a free bibliographic database (PubSCIENCE) for affiliated and unaffiliated users. The authors found that affiliated users had access to more fulltext articles than unaffiliated users had, but the maximum level of fulltext access achieved directly through PubSCIENCE was 45 percent. Both affiliated and unaffiliated users could increase their level of access to full-text content by using alternative avenues for access above and beyond use of the database linkage. However, such additional searching requires a higher level of information literacy on the user's part.
\end{abstract}

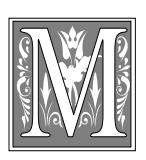

ick O'Leary has noted that

"One of the Web's greatest accomplishments has been to reinforce the notion that all information ought to be free." ${ }^{1}$ So if everything is free on the World Wide Web, why should universities spend millions of dollars on bibliographic and full-text databases for their libraries? The answer often offered by university libraries is deceptively simple. High-quality peerreviewed materials are not always available for free on the Web, and university libraries provide access to journals, conference proceedings, and other peer-reviewed materials through costly agreements with journal publishers and bibliographic and full-text database providers. Mary Ellen Bates has warned: "There ain't no such thing as free lunch." Bates has insisted that free lunch is "onestop access to the archives of a number of periodicals, support for complex searching, and no charge for access, searching, or downloading any available information." ${ }^{2}$

University libraries provide access to full text via a variety of media, including print and electronic. However, such access comes with the caveat that the university, first and foremost, provides access for its own community of students, faculty, and staff. Although anyone may physically enter the library and use its materials, not everyone may enjoy electronic access to bibliographic and full-text databases or to the full text of journal articles via the desktop. Only those officially affiliated with the university have desktop access to the electronic full text of journals, to the electronic bibliographic records, and to the entire spectrum of the university library's digital collection. Users have made clear that they want the

Jill E. Grogg is an Assistant Professor and Instruction Services Librarian in the Mississippi State University Libraries; e-mail: jgrogg@library.msstate.edu. Debra K. Andreadis is the Science Liaison/Reference Librarian in the William Howard Doane Library at Denison University; e-mail: andreadisd@denison.edu. Rachel A. Kirk is a Graduate Student in the School of Information Sciences at the University of Tennessee; e-mail: rkirk1@utk.edu. 
convenience of electronic access to full text. Diane J. Hoffman has stated plainly: "Scholars and researchers expect seamless access to network-accessible materials." 3

The unaffiliated user must explore other options for consistent desktop access to the full text of journal articles. Options available include pay-per-view, full or partial subscription, or, in rare cases, free availability. Fortunately, free full text is becoming more common. New services such as FindArticles.com (the result of a unique partnership between The Gale Group and LookSmart) not only provide free article search services but also deliver the full text for no charge. ${ }^{4}$ Other free full-text options include PubMed Central and BioMed Central. Although more options for free text are becoming available, for the affiliated, the university library remains a crucial subsidizer and information provider for students, faculty, and staff. Imagine if students or faculty were forced to pay for each article they needed for a project or a class. Affiliation affords users the convenience of electronic access to full text, presumably greater access than unaffiliated users enjoy.

Logically, the percentage of full text to which a user has desktop access should be greater for the affiliated user than for the unaffiliated. For the affiliated, access to the full text is available through a variety of sources: aggregators with internal links to a digital collection of full text (e.g., Ovid or OCLC); publishers' Web sites without a secondary search service (e.g., ElsevierScience's ScienceDirect or Springer-Verlag's LINK); the university library's Online Public Access Catalog (OPAC); or free bibliographic databases with external links to publishers' Web sites (e.g., Ask ERIC, PubMed, or PubSCIENCE). The authors of this article are concerned with the latter of these finding aids-free bibliographic databases with external links to full text. Specifically, the authors used PubSCIENCE to examine the percentage of electronic full text to which a university-affiliated graduate student has access versus the percentage of electronic full text to which his or her postgraduate, professional counterpart has access. In other words, for a series of given queries and retrieved relevant documents, the authors examined the percentage of full-text access for affiliated versus nonaffiliated users. For testing purposes, ecology or environmental studies was chosen as a subject area, and the study was conducted at the University of Tennessee (UT), a typical Association of Research Libraries (ARL) institution.

\section{Context of the Case Study}

One route of employment for postgraduate ecology or environmental studies is in the area of environmental consulting. Consulting can be done in a firm or as an individual in a freelance situation. Environmental consulting firms in the Knoxville-Oak Ridge, Tennessee, area vary in size from one to 260 employees, but the large firms are the exception. The median number of employees is four for the fiftynine Knoxville-Oak Ridge firms listed in Dun \& Bradstreet. ${ }^{5}$ Because the firms are relatively small, the high cost to subscribe to or lease large full-text databases or the journals themselves are not viable options. Nor do these firms usually have the funds to lease or subscribe to a bibliographic database. Therefore, the free availability of a bibliographic database, specifically PubSCIENCE, should be an attractive alternative.

PubSCIENCE, according to the Web site, "provides users the capability to search across a large compendium of peer-reviewed journal literature with a focus on the physical sciences and other disciplines of concern to the Department of Energy (DOE)." 6 PubSCIENCE is a bibliographic database service developed by the DOE Office of Scientific and Technical Information (OSTI) and closely modeled after PubMed. The journal citations within the database are contributed by participating publishers, information intermediaries, and the DOE database maintained by OSTI. Likewise, participating publishers provide links within a citation to the full text of journal articles. 
Such links move the user out of the PubSCIENCE environment to the journal publisher's Web site. Bette Brunelle notes that this type of full-text linking is a "nice fit" because:

the publisher model [for full text] lacks a way to make the body of literature searchable-and the distributed model provides it. A large userbase is already comfortable with using bibliographic databases as the gateway to the literature. ${ }^{7}$

If the affiliated user's university or employer has a subscription to the electronic version of the journal, the access to the full text should be seamless. The unaffiliated user, unless he or she maintains a subscription, must explore other options, such as pay-per-view, document delivery, or using another system to find free full-text access. ${ }^{8}$

As mentioned previously, a user affiliated with UT should have seamless access if the UT libraries carry a subscription to the electronic version of the journal. UT is a Carnegie class I institution, and its library system is an ARL member. According to the 2000 edition of The Carnegie Classification of Institutions of Higher Education, UT is a Doctoral/Research University-Extensive. This classification is based on UT's degree-granting activities from 1995-1996 through 1997-1998. ${ }^{9}$ According to ARL statistics, UT awarded 248 Ph.D.'s in 1999, ranking 52nd out of the 111 ARL institutions. The degrees were awarded across forty-five fields, ranking UT 68th out of the 111 ARL institutions. ${ }^{10}$ Of the 111 ARL members, UT is ranked 53rd for total current serials, with 23,094. This total represents the combination of current serials purchased and current serials not purchased. ${ }^{11}$

The ARL Supplementary Statistics 1998 99 indicates that the average dollars spent for electronic serials was $\$ 639,281$. UT reported spending $\$ 449,695$, an expenditure closer to the 1997-1998 average of $\$ 449,971$. For purposes of comparison, following are expenditures for electronic serials from the University of Kentucky (UK), Louisiana State University (LSU), and the University of South Carolina (USC). For 1998-1999, UK spent \$724,098, LSU spent $\$ 221,017$, and USC spent $\$ 582,160 .^{12}$ These three institutions were chosen for comparison because they are UT's competing peer institutions and are similar in size. Taking into consideration individual and institutional policies, decisions, and budgets, the ARL statistics for 1998-1999 indicate that the UT library system is a relatively average ARL institution with a generalizable environment.

\section{Review of Literature}

Greg R. Notess has provided an understanding of the origins of PubSCIENCE and its relationship to PubMed. He clarified the intended scope of PubSCIENCE and explained that the service does not cover all the physical sciences but, rather, only the portion considered of interest to the energy community. His article does not address the main concern of the authors of this article, which is the availability of full text based on access methods (affiliated or unaffiliated). ${ }^{13}$ Peter Jacso also examined PubSCIENCE and compared its competitive value to fee-based databases such as EnergyLine and the DOE Energy Science and Technology Database (ETSD). Jacso specifically examined how PubSCIENCE is both more and less than ETSD. PubSCIENCE provides less than ETSD in its searching capabilities but offers more because PubSCIENCE includes a sister database, the DOE Information Bridge. The Information Bridge offers free access to the full text (PDF format) of DOE reports and gray literature. Jacso concluded that "PubSCIENCE is an excellent resource for those who cannot afford the fee-based databases" and that "it can easily become the preferred source also for those who currently subscribe to one or more of the commercial databases."14

Neither Notess nor Jacso explored the advantages and disadvantages of the fulltext links to publisher Web sites within PubSCIENCE and neglected to discuss 
the implications of these links for affiliated and unaffiliated users. Robert E. Donohue has offered a comprehensive review of PubSCIENCE and has described planned enhancements for the database, including a migration to an ORACLE-based system; and Walter L. Warnick has outlined the history of PubSCIENCE. ${ }^{15,16}$ Like Notess and Jasco, however, neither Donohue nor Warnick commented on access for unaffiliated versus affiliated users. Laura GordonMurnane did compare fee and free alternatives for federal government search tools (FedWorld, usgovsearch.com, Google/Unclesam, and GovBot), concluding that the "best bet is to use multiple engines, fee and free, to achieve better search results," but for affiliated-versus-unaffiliated access, significant opportunities for research remain to be explored. ${ }^{17}$

Brunelle discussed the growing demand for full-text database services. She began by identifying the potential of fulltext linking and then presented three models of how this access is provided as well as the strengths and weakness of each scenario. Brunelle presented the publisher-supplied full-text concept, the aggregator-supplied full-text model, and the distributed "linked" full text. ${ }^{18}$ Lawrence Krumenaker advised researchers on how to navigate between the different scenarios to access needed documents and overcome obstacles posed by the current publishing environment. ${ }^{19}$ Laurie A. Preston, Corinne M. Ebbs, and Judy Luther tested the value of full-text access through a sampling of journal issues available online and provided a model for evaluating the true functionality of full-text databases. ${ }^{20}$ Walt Crawford has discussed the disadvantages of relying exclusively on one access method. ${ }^{21}$

Jacso examined one- and bi-directional linking and the accompanying partnerships between publishers and companies. ${ }^{22} \mathrm{He}$ also examined new models of access to full text, including Northern Light, Contentville, Electric Library, and FindArticles.com. These services offer the bibliographic records for free and employ several models of providing the full text. Northern Light and Contentville have a pay-per-view option for full text, but as Jacso noted, the price is "only a fraction of what you would pay to traditional document delivery services. ${ }^{23}$ FindArticles.com provides the full text from 300 journals for free, and the Electric Library offers unlimited full-text access in exchange for a monthly fee, less than $\$ 10$ according to Jacso. Ann Okerson has offered a discussion about the history and future of e-journal linking. ${ }^{24}$

Based on the review of the literature, there appears to be no current research that compares the full-text linking feature of free bibliographic databases, such as PubSCIENCE, by access method. However, enough work has been done in the field of database comparison to underscore the significance of this area of research, and tested, widely accepted methodologies exist to use in the endeavor.

\section{Methodology: Phase One}

The authors of this article developed ten questions in the field of ecology by interviewing researchers at two environmental consulting firms about the kinds of projects on which they worked (table 1). From examples of projects, one of the authors, who has advanced subject knowledge of ecology, crafted questions. The questions were designed to be broad enough to assume major journal coverage and narrow enough to provide a basis for evaluating relevance and precision. Identical literature search topics were run simultaneously in PubSCIENCE, one search as an affiliated user with a UT account and one as an unaffiliated user with an America Online (AOL) subscription account. The searches were performed at the same time on two adjacent computers.

In PubSCIENCE, the search was restricted to articles available in full text so as to eliminate any purely bibliographic results. When search results were retrieved for each of the ten queries, the affiliated and unaffiliated searchers fol- 


\begin{tabular}{|c|c|}
\hline \multicolumn{2}{|c|}{$\begin{array}{c}\text { TABLE } 1 \\
\text { PubSCIENCE Questions and Search Strategies }\end{array}$} \\
\hline Question & Strategy \\
\hline $\begin{array}{l}\text { 1. What are the effects of water warming } \\
\text { by hydroelectric plants on fish? }\end{array}$ & $\begin{array}{l}\text { (hydroelectr* OR power plant*) AND } \\
\text { fish* AND warm* }\end{array}$ \\
\hline $\begin{array}{l}\text { 2. What are the deleterious effects on } \\
\text { PCBs on wildlife? }\end{array}$ & $\begin{array}{l}\text { (pcb* OR polychlorinated biphenyl*) } \\
\text { AND (wildlife OR waterfowl OR wild } \\
\text { animal*) }\end{array}$ \\
\hline $\begin{array}{l}\text { 3. Does mercury contamination affect } \\
\text { amphibian development? }\end{array}$ & $\begin{array}{l}\text { mercur* AND (amphibia* OR frog* OR } \\
\text { salamander* OR toad*) AND (develop* } \\
\text { OR metamorphos*) }\end{array}$ \\
\hline $\begin{array}{l}\text { 4. How does clear-cutting impact small } \\
\text { mammal populations? }\end{array}$ & $\begin{array}{l}\text { (clearcut* OR clear-cut* OR clear cut*) } \\
\text { AND small AND mammal }\end{array}$ \\
\hline $\begin{array}{l}\text { 5. Does wastewater treatment increase } \\
\text { forest productivity? }\end{array}$ & $\begin{array}{l}\text { (wastewater OR sewage) AND forest* } \\
\text { AND treatment }\end{array}$ \\
\hline $\begin{array}{l}\text { 6. Are reconstructed or man-made } \\
\text { wetlands used by wildlife as readily as } \\
\text { natural wetlands? }\end{array}$ & $\begin{array}{l}\text { (reconstruct* OR construct* OR man- } \\
\text { made) AND (wetland* OR marsh*) }\end{array}$ \\
\hline $\begin{array}{l}\text { 7. What toxins in fish pose the greatest } \\
\text { hazards to human health? }\end{array}$ & $\begin{array}{l}\text { fish* AND toxi* AND human AND } \\
\text { consum* }\end{array}$ \\
\hline $\begin{array}{l}\text { 8. Is drinking water near superfund sites } \\
\text { a health hazard? }\end{array}$ & water* AND superfund \\
\hline $\begin{array}{l}\text { 9. Can microbes be genetically engi- } \\
\text { neered to remove heavy metals from } \\
\text { streams? }\end{array}$ & $\begin{array}{l}\text { microb* AND genetic* AND engineer* } \\
\text { AND (heavy metal* OR lead OR mercur*) }\end{array}$ \\
\hline $\begin{array}{l}\text { 10. Can wastewater be effectively filtered } \\
\text { to produce drinking water by biologi- } \\
\text { cal rather than chemical means? }\end{array}$ & $\begin{array}{l}\text { (wastewater OR sewage) AND drink* } \\
\text { AND biolog* }\end{array}$ \\
\hline
\end{tabular}

lowed the full-text links from the bibliographic records to the publishers' Web sites. The authors then noted access to full text for the affiliated (UT) and unaffiliated (AOL) approaches. After all ten searches were performed and all links to full text explored, the total number of full-text articles available for the affiliated-versusunaffiliated user was examined and tested for significance with a chi square contingency test.

The subject expert then evaluated the ten result sets. Excluding articles to which the affiliated and unaffiliated searchers had full-text access through a link in PubSCIENCE, she chose the most relevant article from each set, thus producing a list of ten relevant articles. Using this list, the authors attempted to find the articles' full text via avenues other than PubSCIENCE.

For the affiliated user, the authors searched:

- UT's Online Public Access Catalog (OPAC)

- UT's e-journal list (electronic journals to which the UT subscribes either individually or as a package from specific publishers)

- A document delivery service (Carl UnCover)

- Several commercial full-text databases (Lexis-Nexis, ProQuest, JSTOR, 
Dow Jones Interactive, Gale Group's InfoTrac, and ScienceDirect)

For the unaffiliated user, the authors searched free Web sources and noted prices where available:

- HighWire Press

(http:/ / highwire.stanford.edu)

- Google

(http:/ / www.google.com)

- Northern Light Special Collection (http:/ / www.northernlight.com/ docs/specoll_help_overview.html)

- FindArticles.com

(http:/ / www.findarticles.com)

In Google, the authors searched using article title, and the results retrieved were few enough that all results were examined. The authors searched using journal title in HighWire, Northern Light, and FindArticles.com.

\section{Methodology: Phase Two}

Because the percentages of returned articles from phase one were surprisingly low (with only $12 \%$ return for the affiliated searcher and 3\% for the unaffiliated), the authors considered the possibility that the research topic, though certainly a valid field of inquiry, may have been overly specific for this database, thereby skewing the results. Therefore, the scope of the searches was expanded and the authors used a second approach for searching the PubSCIENCE database. This approach assumed that if one were to examine each publisher represented in the PubSCIENCE database by selecting two of its journals and attempting to retrieve a full-text article from each, the results would better represent the percentage of full-text articles available via the PubSCIENCE database. A single, ubiquitous term was used ("state") to search each publisher subset of the database. If only one journal title was returned, it was checked against the list of titles present from that publisher. In all cases, a single title returned was the only title provided by the publisher in question. For the publishers that had multiples titles present in PubSCIENCE, the authors looked at two publications
TABLE 2

Number of Returns Accessible for Each of the Ten Questions

\begin{tabular}{lcc}
\hline \hline Question & $\begin{array}{c}\text { Affiliated } \\
\text { (UT) }\end{array}$ & $\begin{array}{c}\text { Unaffiliated } \\
\text { (AOL) }\end{array}$ \\
\hline 1 & $0 / 5$ & $0 / 5$ \\
2 & $5 / 27$ & $0 / 27$ \\
3 & $0 / 6$ & $0 / 6$ \\
4 & $2 / 31$ & $2 / 31$ \\
5 & $0 / 18$ & $0 / 18$ \\
6 & $2 / 22$ & $0 / 22$ \\
7 & $7 / 30$ & $1 / 30$ \\
8 & $2 / 13$ & $1 / 13$ \\
9 & $2 / 5$ & $1 / 5$ \\
10 & $1 / 12$ & $0 / 12$ \\
\hline Total & $21 / 169$ & $5 / 169$ \\
\hline
\end{tabular}

from each. Again, the titles were explored simultaneously on an affiliated computer (UT) and an unaffiliated (AOL) computer. The total number of links followed in this manner was fiftyeight from a total of thirty-three publishers, with eight publishers providing a single journal.

The authors repeated the tracking of unavailable works as described in phase one for the affiliated and unaffiliated user. The same sources were searched as previously, with the exception of the change from the Carl UnCover service to Ingenta.com, which had purchased UnCover in the interim. All thirty-two articles that were not retrieved by the affiliated user were pursued in this manner.

\section{Results: Phase One}

As shown in table 2, affiliated users had better access than unaffiliated users. To test to see whether this difference was significant, the authors used a chi-square contingency test and, as table 3 shows, the difference was highly significant $(\mathrm{p}=$ 0.002). Still, very few of the articles returned were available in full text for either the affiliated or the unaffiliated user.

The full text of some of the articles retrieved should have been available to af- 
filiated or unaffiliated users, but the links from PubSCIENCE were not working properly. Six articles of the 169 had broken links. One article was posted in the wrong font so that the title appeared in Greek characters, even though it was an English-language title. Many of the retrieved articles were from the same publisherNRC from Canada. NRC has changed its URL, and PubSCIENCE does not reflect this change. When NRC titles

\begin{tabular}{|lcc|}
\hline \multicolumn{3}{c|}{ TABLE 3} \\
Chi-square Contingency Table for \\
Comparing Access for Affiliated and \\
Unaffiliated Users From Phase One \\
\hline \hline Affiliation & \# Articles & \# Articles Not \\
& Accessible & Accessible \\
\hline UT & 21 & 148 \\
AOL & 5 & 164 \\
\hline Total & $21 / 169$ & $5 / 169$ \\
\hline
\end{tabular}
are accessed, the user is redirected to the home page of the publisher where it is then necessary to ferret out the journal and article of interest.

The authors then sought to find the most relevant articles (one from each of the ten sets) through avenues other than links from PubSCIENCE. For the affiliated user, two of ten are available online without a fee. One is available through ProQuest; the other is available through the UT e-journals page. Of these two articles, only the one found in a journal

The lack of additional access via the Web or low-cost pay-per-view services such as Northern Light was very disappointing.

listed on the UT e-journals page is tagged in the OPAC as being available in an online version. The journal containing the article available via ProQuest is not tagged in the OPAC, even though UT has a print subscription. None of the articles is available via any of the visited Web avenues.

Going beyond electronic full-text options, two additional titles were available via UnCover for the affiliated user at no charge (although these titles are held by UT in print, they are not listed as such in the UnCover database). For the affiliated user, then, four of the ten titles are available at no charge without requiring a trip to the library. One title is available via UnCover for a fee of $\$ 19.50$, which UT would not subsidize because the title is listed in UnCover as being owned in print. Another three titles are available

from the publisher for $\$ 20.00$ each. Thus, for a total charge of $\$ 79.50$, eight of the ten articles could be recovered via the computer or fax machine.

For the unaffiliated user, the only methods of access were ordering directly from the publisher for a fee and UnCover for a fee. Four were available via UnCover (three at \$14.50 each and one at \$19.50), and three additional titles were available directly from the publisher for $\$ 20$ each. The unaffiliated user could receive seven of the ten articles for a total charge of $\$ 123$.

For either the affiliated or unaffiliated user, five of the titles are available in print form in the UT library. All of these also are available by one of the other previously mentioned methods for UT users, although two if the titles would incur charges. For the unaffiliated user, one additional print title is accessible that is not available via electronic means. Table 4 summarizes the findings for the affiliated and unaffiliated user for both fee and no fee access via avenues other than links from PubSCIENCE.

\section{Results: Phase Two}

The suspicion that the subject specificity (ecology) employed in phase one skewed the results proved to be true. In phase two, the authors examined a more systematic cross section of the database and found that the percentage of access to fulltext articles increased in both affiliated and unaffiliated users. As table 5 shows, affiliated users still had better access than unaffiliated users $(\mathrm{p}=0.002)$.

Overall, the percentages of accessible articles were greater when all publishers 


\begin{tabular}{|lcc|}
\hline \multicolumn{3}{|c|}{$\begin{array}{c}\text { TABLE } 4 \\
\text { Fee and No Fee Access for Affiliated and } \\
\text { Unaffiliated Users from Phase One }\end{array}$} \\
\hline \hline Access Means & $\begin{array}{c}\text { Affiliated } \\
\text { (UT) }\end{array}$ & $\begin{array}{c}\text { Unaffiliated } \\
\text { (AOL) }\end{array}$ \\
\hline Full-text databases & 1 & 0 \\
UT e-journals page & 1 & 0 \\
Free Web & 0 & 0 \\
UnCover (no fee) & 2 & 0 \\
UnCover (fee) & 1 & 4 \\
Publisher (fee) & 3 & 3 \\
\hline Total & 8 & 7 \\
\hline
\end{tabular}

available in the OPAC, two from Dow Jones and two from ProQuest, but none of the articles needed was available from these sources.

Six additional titles were available via Ingenta.com for the affiliated user with no fee (the print version is not available from UT and the charge for each article is less than UT's maximum allowable subsidy of \$35). This means that the affiliated user can view fourteen of the thirty-two titles for no

were sampled in this set of results $(45 \%$ for affiliated users; $14 \%$ for unafffiliated users). The ratio of articles retrieved by unaffiliated users versus articles retrieved by affiliated users shifted from 24 to 31 percent. Given the broad selection of publishers sampled and the fact that electronic access is usually determined at the publisher level as opposed to the individual journal level, 31 percent appears to be a reasonable estimate for the percentage of electronic access attained by unaffiliated users compared to affiliated users.

Problems also arose in this set with broken links and links that led the user to the publisher's Web site or journal Web site rather than to the actual article of interest. This occurred in seven of the fiftyeight articles tested.

The authors again sought to find the articles not listed as available via the catalog link through other avenues (table 6). For the affiliated user, eight of thirty-two not available via links in PubSCIENCE are available online without a fee. One is available via the UT e-journal list, three through ScienceDirect, one through InfoTrack, one preprint is available via the Web, and two others are available directly from the Web (one found via Google and one free with registration at the journal publisher's page). Of these eight articles, only the one found in a journal listed on the UT e-journals page is tagged in the OPAC as being available in an online version. Four additional journals are tagged as being charge and without requiring a trip to the library. Six additional titles are available via Ingenta.com for a total cost of \$132.37, which UT will not pay because it owns the titles in print form. Four additional titles are available from the publisher for a combined fee of $\$ 151$. Thus, for a total charge of \$283.37, twenty-four of the thirty-two articles could be recovered via the computer or fax machine.

For the unaffiliated user, the three previously identified articles were available free via the Web (preprint, Google, registration at the journal publisher's page). The only other successful means of access was to order directly from the publisher for a fee and from Ingenta.com for a fee. Fifteen were available from Ingenta.com for a total cost of \$355.16, and four additional titles were available directly from the publisher for a total cost of $\$ 151$. The unaffiliated user could receive twenty-two of the thirty-two articles (articles originally not available through PubSCIENCE for the affiliated user) for a total charge of $\$ 506.16$.

\section{TABLE 5}

Chi-square Contingency Table for Comparing Access for Affiliated and Unaffiliated Users From Phase Two

\begin{tabular}{lcc}
\hline Affiliation & $\begin{array}{c}\text { \#Articles } \\
\text { Accessible }\end{array}$ & $\begin{array}{c}\text { \# Articles Not } \\
\text { Accessible }\end{array}$ \\
\hline UT & 26 & 32 \\
AOL & 8 & 50 \\
\hline
\end{tabular}




\begin{tabular}{|lcc|}
\hline \multicolumn{3}{|c|}{ TABLE 6} \\
\multicolumn{2}{|c|}{$\begin{array}{c}\text { Fee and No Fee Access for Affiliated and } \\
\text { Unaffiliated Users from Phase Two }\end{array}$} \\
\hline \hline Access Means & $\begin{array}{c}\text { Affiliated } \\
\text { (UT) }\end{array}$ & $\begin{array}{c}\text { Unaffiliated } \\
\text { (AOL) }\end{array}$ \\
\hline Full-text databases & 4 & 0 \\
UT e-journals page & 1 & 0 \\
Free Web & 3 & 3 \\
Ingenta.com (no fee) & 6 & 0 \\
Ingenta.com (fee) & 6 & 15 \\
Publisher (fee) & 4 & 4 \\
\hline Total & 24 & 22 \\
\hline
\end{tabular}

cess increased for the affiliated user $(20 \%$ and $44 \%$ retrieval for each phase, respectively). However, this process involved a lot of additional searching and still yielded a surprisingly low return for the effort. The outlook for the unaffiliated user is even bleaker. The lack of additional access via the Web or low-cost payper-view services such as Northern Light was very disappointing.

There were other options

Fourteen of the thirty-two titles are available in print form within the library. Four of them are unavailable in any other format mentioned previously for the affiliated user. The six titles available for a fee from Ingenta.com are free in print form within the library.

\section{Discussion}

Although PubSCIENCE is a good resource for the unaffiliated user to gain access to bibliographic information on scientific literature, it is not particularly useful for retrieving full text. Part of the problem was created by broken or outof-date links. This also affected affiliated users because some of the broken links pointed to journals to which UT has electronic subscriptions. Although these links should take users directly to the full text of the articles, they, instead, send users to the front page of the publisher, thus forcing the user to search for the article of interest.

Although affiliated users could access more articles in full text (tables 3 and 5), the authors were surprised to find how few articles were available in full-text form $(12 \%$ to $45 \%)$, even to the affiliated user, directly through PubSCIENCE. However, access is even more limited for the unaffiliated user: Electronic access to the full text without charge was found for only 3 to 14 percent of the articles.

When search efforts were restricted to articles unavailable by direct means through PubSCIENCE, free electronic ac- for retrieving the articles to the desktop or office without having to make a trip to the library. These included paying for a copy directly from the publisher or using a document delivery service (UnCover/ Ingenta.com). These options greatly increased the percentage of articles that could be accessed (up to $80 \%$ for the affiliated user and $70 \%$ for the unaffiliated user in phase one; $75 \%$ for affiliated and $69 \%$ for unaffiliated in phase two), but the coverage of these services overlaps somewhat. Therefore, the user would have to run searches in multiple databases to find the best price available for office delivery. The total price to recover the articles may be prohibitive as well. There are complications even for the affiliated user with document delivery services because in phase one the UnCover documents for UT-affiliated users includes one title that is actually held by UT. This would put UT in the position of paying for access to a volume that it holds in its collection or of informing the user that he or she must pay for the document delivery service charge after the fact. The lack of connection from the OPAC to alternative delivery options also is problematic. Having to search in all the various places that fulltext access might be found is time-consuming and requires knowledge that the average user may not have.

\section{Conclusion}

Research in the first phase was skewed by the fact that only a limited set of jour- 
nals in PubSCIENCE had relevant articles for the authors' topic. Because the subject area was not well represented by journals within PubSCIENCE, the results were biased by one particular publisher's journals that came up repeatedly. The overall results when including all publishers were more encouraging, but fewer than half of all the articles were available directly from the connections made from PubSCIENCE. This means that an affiliated user, as represented by student enrolled at the University of Tennessee, who searches the PubSCIENCE database can obtain direct and free access to 12 to 45 percent of the articles that meet the criteria of a search strategy. The unaffiliated user, unfortunately, will be only 24 to 31 percent as successful as the affiliated user. Exclusive reliance on PubSCIENCE for full-text articles results in a greater than 50 percent chance that an affiliated user will be unable to retrieve an article for free. For unaffiliated users, only a 3 to 12 percent probability of direct and free fulltext access exists.

On the whole, PubSCIENCE is a good bibliographic resource for all users and also may be a good resource for full-text access, depending on the number of journals to which an affiliated user's organization subscribes. However, this access comes with a caveat: Even if the user's organization has a subscription to a specific journal, access may take the form of other online full-text services or only a print subscription. In addition, because the links in PubSCIENCE point to publishers' Web sites, access to full text may be denied. Further, because there are so many options for full-text delivery, academic institutions are faced with linking OPAC records for journals and integrating records for their subscribed bibliographic databases, subscribed full-text databases, and direct subscriptions to publisher-supplied full text, among other options.

To return to the question posed at the beginning of this article, the brief foray into the unaffiliated world proves that all information is not free via the Web. As a matter of fact, very little high-quality scholarly information is available for free via the Web. Perhaps Bates is correct, "There ain't no such thing as free lunch." 25

\section{Notes}

1. Mick O’Leary, “Gale Goes Free,” Econtent 23, no. 6 (Dec. 2000): 71-73.

2. Mary Ellen Bates, "Tanstaafl: In Search of the Free Lunch and No-Cost/Low-Cost Fulltext Archives," Searcher 8, no. 6 (June 2000): 55-59.

3. Diane J. Hoffman, "Think Links: Full-text Linking Projects," Online 25, no. 1 (Jan./Feb. 2001): 40-46.

4. Peter Jacso, "FindArticles.com Embraces Free Content Trend," Information Today 17, no. 10 (Nov. 2000): 38-40; O'Leary, "Gale Goes Free."

5. Dun \& Bradstreet. 2001. Dun's Market Identifiers. Databases online. Available via DialogClassic from http:/ / www.dialogclassic.com/. (Accessed 17 February 2001.)

6. Department of Energy Office of Scientific and Technical Information. 2001. PubSCIENCE. Available from http:/ / pubsci.osti.gov. (Accessed 15 February 2001.)

7. Bette Brunelle, "Quieting the Crowd: The Clamour for Full Text," Online E CD-ROM Review 23, no. 5 (Oct. 1999): 297-302.

8. Jill E. Grogg and Carol Tenopir, "Linking to Full Text in Scholarly Journals: Here a Link, There a Link, Everywhere a Link." Searcher 8, no. 10 (Nov./Dec. 2000): 36-42.

9. The Carnegie Classification. 2000. Available from http:/ / www.carnegiefoundation.org/Classification/. (Accessed 16 February 2001.)

10. Ibid.

11. Association of Research Libraries. 2000. "Association of Research Libraries Statistics." Available from: http:/ / fisher.lib.virginia.edu/arl/index.html. (Accessed 16 February 2001.)

12. Martha Kyrillidou, comp. and ed., ARL Supplementary Statistics 1998-99 (Washington, D.C.: Association of Research Libraries, 2000), available from http:/ / www.arl.org/stats/sup/ sup99.pdf. (Accessed 16 February 2001.)

13. Greg R. Notess, "PubSCIENCE: Evolution or Devolution," Econtent 23, no. 1 (Feb. 2000): 64-66. 
14. Peter Jacso, “Energy Science and Technology," Link Up 17, no. 3 (May/June 2000): 3, 8.

15. Robert E. Donohue, "PubSCIENCE: Accessing Scientific and Technical Journal Information at the Desktop," Serials Review 27, no. 1 (2001): 18-25.

16. Walter L. Warnick, "PubSCIENCE: Hyperlinking to the Physical Sciences," Learned Publishing 14, no. 1 (Jan. 2001): 65-67.

17. Laura Gordon-Murnane, "Government Search Tools: Evaluating Fee and Free Search Alternatives," Searcher 7, no. 8 (Sept. 1999): 66-76.

18. Brunelle, "Quieting the Crowd."

19. Lawrence Krumenaker, "A Dillar, a Dollar-Where's That Online Article, Scholar?" Searcher 7, no. 8 (Sept. 1999): 36-40.

20. Laurie A. Preston, Corinne M. Ebbs, and Judy Luther, "Full-text Access Evaluation: Are We Getting the Real Thing? At James Madison University, Report of a Workshop at the 1997 NASIG Conference," Serials Librarian 34, no. 3/4 (1998): 301-5.

21. Walt Crawford, "Here's the Content-Where's the Context?; What Vendors Won't Tell You about Full-Text," American Libraries 31, no. 3 (Mar. 2000): 50-52.

22. Jacso, "Partnerships on the Web," Computers in Libraries 21, no. 1 (Jan. 2001): 72-75.

23. "Finding Free Databases to Replace Fee-based Information Services," Computers in Libraries 20, no. 10 (Nov./ Dec. 2000): 61-62.

24. Ann Okerson, "Are We There Yet? Online E-resources Ten Years After," Library Trends 48, no. 4 (spring 2000): 671-93.

25. Bates, "Tanstaafl." 